\title{
Visualization of data on cash in Russia
}

\begin{abstract}
Annotation
The article proposes to use the average per capita cash income of the population, which can characterize its stability over time, as a generalized indicator of the stability and development of the social system (for example, the Russian Federation). The analysis of the available baseline data on average per capita monetary incomes of the population of Russia for 2012-2018 has been carried out, deficiencies in the formation of the initial data are noted. It is proposed to draw a conclusion about the stability of the social system on the basis of the Lorenz curve.
\end{abstract}

Keywords: social system, Lorenz curve, ginny coefficient
Volume 7 Issue 5 - 2019

\author{
Lebedev Alexey Viktorovich,' Bochkov \\ Alexander Petrovich ${ }^{2}$ \\ 'Professor of Mathematics and Information Technology, Moscow \\ University named after Witte, Russia \\ ${ }^{2}$ Professor, Department of Applied Mathematics, Peter the Great \\ St. Petersburg Polytechnic University, Russia
}

\begin{abstract}
Correspondence: Lebedev Alexey Viktorovich, doctor of technical sciences, Professor of Mathematics and Information Technology, Moscow University named after Witte, Russia, Tel +7-960-7058967, Email lebedevavic@rambler.ru
\end{abstract}

Received: June 27, 2019 | Published: September 27, 2019

\section{Review}

The stability of the social system are its most important characteristics. However, mathematical models of their location do not exist. ${ }^{1}$ Stability is a common property of the social system. It can be considered in two forms: resistant stability, that is, the ability of the social system to remain in a steady state under stress, and elastic stability, that is, the ability of the system to quickly restore its initial parameters. Stability is understood as the internal ability of the system to remain in a state close to equilibrium and to return to it after various disturbances, and under stability to maintain a relatively unchanged state under the influence of no significant changes in the external environment. Violation of the stability of the system leads to deviations, one of the manifestations of which is the increase in crime. Each social system is self-regulating. In its information subsystem laid down the norms of reaction to various external disturbing influences. If the social system is stable in general to all influences in the external environment, in this case, it enters a state that can be characterized by the notion of "stability". Stability, therefore, represents the composition of the system's resistances to various influences. ${ }^{2}$

However, fully stable systems are not capable of development and degrade over time, and social systems that are resistant to one or another factor are not necessarily stable. Stability is associated with the overall structural and functional organization of the system throughout its entire existence, stability with its individual structural and functional indicators and mostly short periods of time. Each stable system is dynamic and, depending on the processes occurring in it, we can talk about a decrease (or increase) of stability or its constant level. A constant level of stability, as a rule, provides fluctuation changes. However, the majority of works on the stability of social systems consider this question only at a qualitative level. ${ }^{3}$ The purpose of this work is to formulate quantitative approaches to assessing the sustainability of the social system. As well as the visualization of a number of signs that has a decisive impact on the stability of the social system. The distribution of a trait is called the pattern of occurrence of its different values. In biological and social systems, normal distribution is most often used. The normal distribution is characterized by the fact that the extreme values of the trait in it are quite rare, and values close to the average value are quite often. The normal distribution graph is a bell-shaped curve.

It is believed that the normal distribution characterizes such random variables that are affected by a large number of various factors, and the strength of the impact of one single factor is much less than the sum of the effects of other factors. As a result, it turns out that more often some average values of the measured parameter are observed, less often the extreme ones, and the more a certain value differs from the average, the less often it occurs. Many biological parameters are distributed in a similar way and at the same time show good resistance. Consider the distribution of the population of the Russian Federation in terms of per capita cash income (Table 1).

Table I Distribution of population by per capita cash income in percents

\begin{tabular}{lccccccc}
\hline Year & 2012 & $\mathbf{2 0 1 3}$ & $\mathbf{2 0 1 4}$ & $\mathbf{2 0 1 5}$ & $\mathbf{2 0 1 6}$ & $\mathbf{2 0 1 7}$ & $\mathbf{2 0 1 8 I )}$ \\
\hline $\begin{array}{l}\text { Whole population, \% } \\
\text { Including with average per capita cash income per month, rub.: }\end{array}$ & 100 & 100 & 100 & 100 & 100 & 100 & 100 \\
below 7 000,0 & 12,6 & 9,8 & 8,1 & 6,2 & 6,0 & 5,5 & 5,1 \\
above 7 000, I below 9 000,0 & 7,9 & 6,8 & 6,1 & 5,1 & 5,0 & 4,7 & 4,4 \\
above 9 000,I below 12 000,0 & 12,0 & 10,8 & 10,0 & 8,9 & 8,8 & 8,5 & 8,1 \\
above 12 000, I below 15 000,0 & 10,8 & 10,3 & 9,8 & 9,2 & 9,1 & 8,9 & 8,6 \\
\hline
\end{tabular}




\begin{tabular}{|c|c|c|c|c|c|c|c|}
\hline Year & 2012 & 2013 & 2014 & 2015 & 2016 & 2017 & $20181)$ \\
\hline above 15000,1 below 20000,0 & 14,6 & 14,5 & 14,4 & 14,0 & 14,0 & 13,9 & 13,5 \\
\hline above 20000 , I below 25000,0 & 10,7 & 11,2 & 11,4 & 11,6 & 11,6 & 11,7 & 11,6 \\
\hline above 25000 , I below 30000,0 & 7,8 & 8,4 & 8,8 & 9,2 & 9,2 & 9,4 & 9,4 \\
\hline above 30000 , I below 35000,0 & 5,6 & 6,3 & 6,7 & 7,2 & 7,3 & 7,4 & 7,5 \\
\hline above 35000 , I below 40000,0 & 4,1 & 4,7 & 5,1 & 5,6 & 5,7 & 5,8 & 6,0 \\
\hline above 40000 , I below 50000,0 & 5,4 & 6,3 & 7,0 & 7,9 & 7,9 & 8,2 & 8,5 \\
\hline above 50000, I below 60000,02 ) & 8,5 & 3,8 & 4,2 & 4,9 & 5,0 & 5,2 & 5,4 \\
\hline above 60000, I below 70000,03 ) & $\ldots$ & 7,1 & 2,7 & 3,1 & 3,2 & 3,3 & 3,6 \\
\hline above 70000,0 & $\ldots$ & $\ldots$ & 5,7 & 7,1 & 7,2 & 7,5 & 8,3 \\
\hline
\end{tabular}

Previously, the author showed, ${ }^{4}$ that, in the general case, the material, personnel and information resources influence the behavior of the system. In our opinion, the strongest and fastest influence on the behavior of the social system and its structure can have such a part of the material resource as the incomes of its citizens. Refer again to the table above. This table is cunning in and of itself, since citizens' incomes are formed at intervals of different widths. From our point of view, it would be more correct to re-form the table in the following form (Table 2). This table seems to us more fair to analyze. We will construct a histogram for the distribution of the population of the Russian Federation in terms of per capita cash income in 2018 (Figure $1)$.

Table 2 Distribution of population by per capita cash income (at equal intervals), in percent

\begin{tabular}{|c|c|c|c|c|c|c|c|}
\hline Year & 2012 & 2013 & 2014 & 2015 & 2016 & 2017 & 2018 \\
\hline Whole population, \% & 100 & 100 & 100 & 100 & 100 & 100 & 100 \\
\hline \multicolumn{8}{|c|}{ Including with average per capita cash income per month, rub .: } \\
\hline below 9000,0 & 20,5 & 16,6 & 14,2 & 11,3 & II & 10,2 & 9,5 \\
\hline above $9000, I$ below 20000,0 & 37,4 & 35,6 & 34,2 & 32,1 & 31,9 & 31,3 & 30,2 \\
\hline above 20000 , I below 30000,0 & 18,5 & 19,6 & 20,2 & 20,8 & 20,8 & 21,1 & 21 \\
\hline above 30000 , I below 40000,0 & 9,7 & 11 & 11,8 & 12,8 & 13 & 13,2 & 13,5 \\
\hline above 40000 , I below 50000,0 & 5,4 & 6,3 & 7,0 & 7,9 & 7,9 & 8,2 & 8,5 \\
\hline above 50000, I below 60000,02 ) & 8,5 & 3,8 & 4,2 & 4,9 & 5,0 & 5,2 & 5,4 \\
\hline above 60000, I below 70000,03 ) & $\ldots$ & 7,1 & 2,7 & 3,1 & 3,2 & 3,3 & 3,6 \\
\hline above 70000,0 & $\ldots$ & $\ldots$ & 5,7 & 7,1 & 7,2 & 7,5 & 8,3 \\
\hline
\end{tabular}

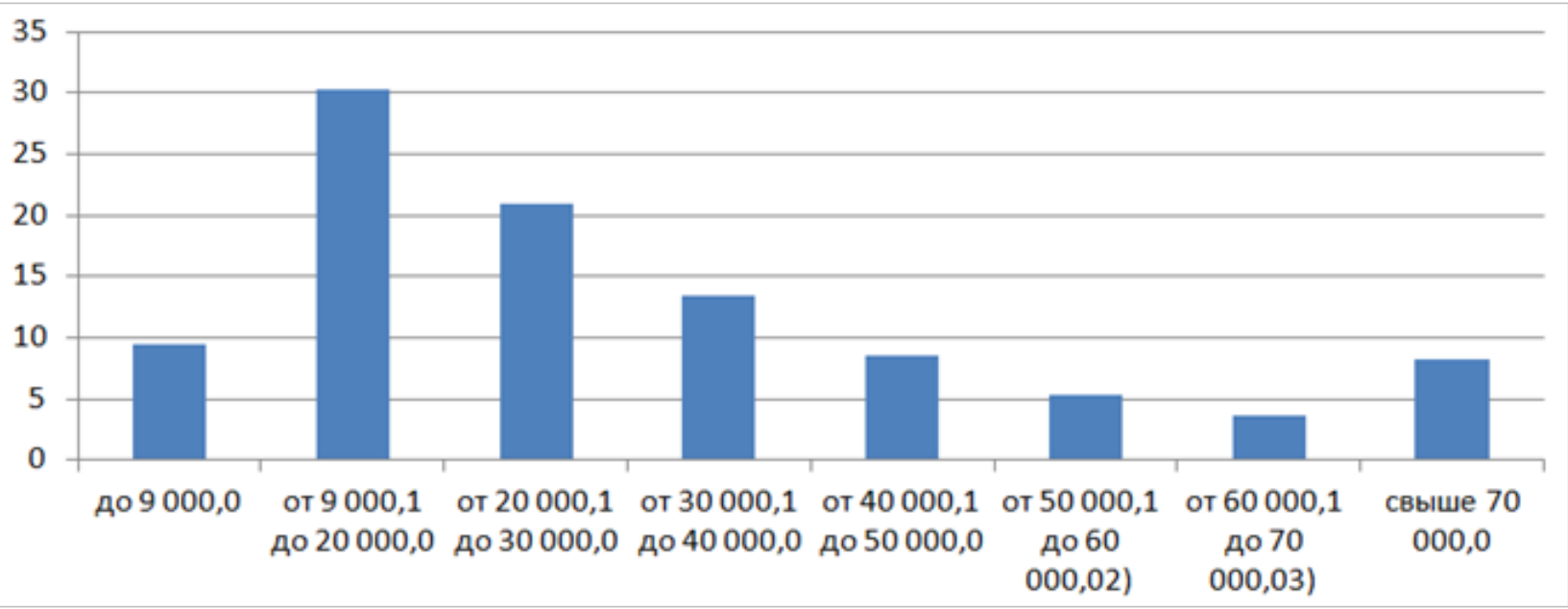

Figure I Distribution of the population of the Russian Federation by per capita cash income in 2018. 
Below is a similar histogram for the distribution of the population of the Russian Federation in terms of per capita cash income in 2012. As we see the changes in these diagrams are positive, but not significant. If there are 8 groups, that is, the average group size is $12.5 \%$, for 2018 there are 3 groups (from 9,000.1 to 20,000.0, from $20,000.1$ to $30,000.0$ and from $30,000.1$ to 40000.0 rubles) are outside this interval. Moreover, for the two groups (from 20,000.1 to 30,000.0 and from 30,000.1 to 40,000.0 rubles), this excess is significant (more than 1.5 times). The distribution is obviously not uniform, but we do not observe any catastrophic deviations (Figure 2).

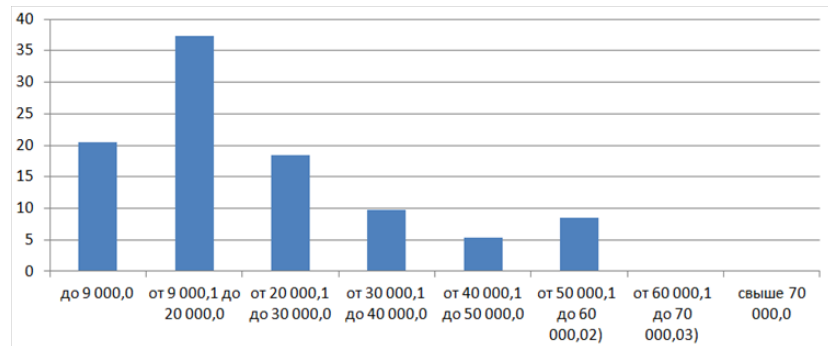

Figure 2 Distribution of the population of the Russian Federation by per capita income in 2012 .

However, this table also has the corresponding cunningness, enclosed in the last line, which shows the average per capita cash incomes for citizens with incomes above 70,000 rubles. Following the table above, it can be concluded that either in 2012 in the Russian Federation either there were no citizens with incomes above 60,000 rubles, or their number was within the measurement error, which is not defined for this table, but it can be assumed that it is half the last significant figure or $0.05 \%$ of the population of the Russian Federation (or $5 * 10-4 * 15 * 107=75,000$ people). This estimate seems plausible. For the data of 2017, it should be noted that the total capital of the 200 most wealthy Russians grew in 2017 to 485 billion dollars. (For reference: the gold and foreign exchange reserves of the Central Bank at this point in time were 433 billion dollars, and the cash savings of all citizens of the Russian Federation in banks (about 389 billion dollars).

The richest citizens of Russia (people with a fortune of $\$ 5$ million) became rich in 2017 by $22-27$ percent, having achieved a fortune of $\$ 1.2$ trillion, or $73.5 \%$ of the country's GDP. The number of citizens with a fortune of 5-50 million dollars (up to 38,120 people) and citizens with a fortune of 50-500 million dollars (up to 2,620 people) increased by $27 \%$ in 2017 , the annual report of The Wealth Report of Knight Frank says . Also by $22 \%$ (to 220 citizens) the number of people whose property is estimated at more than 500 million dollars has increased. Based on the above data, in our opinion, the table should be supplemented with another line "per capita cash income in 2017 of the richest citizens of the Russian Federation". The share of these citizens in the total number of citizens will be 200/150000000 = $1.3 * 10-6$. And the estimate of average per capita income at the lowest estimate of $20 \%$ of 485 billion dollars will be $485 * 106 * 60 * 0.2 / 12 / 200$ $=2425000$ rubles. Once again, this is the lowest estimate (Table 3).

The histogram built by us for 2017 also differs little from the previous ones, but this is due to the existing stereotypes in the construction of histograms. Firstly, when building, the scale is not observed along the axis and this colossal income gap is not visible, and secondly, the share of individuals with specified incomes is so small that it seems that it has no effect on the overall stability of the system (Graph 1).

Table 3 Distribution of population by per capita cash income (in equal intervals with the estimate for the 200 most affluent citizens), as a percentage

\begin{tabular}{|c|c|c|c|c|c|c|c|}
\hline & 2012 & 2013 & 2014 & 2015 & 2016 & 2017 & 2018 \\
\hline Whole population, $\%$ & 100 & 100 & 100 & 100 & 100 & 100 & 100 \\
\hline \multicolumn{8}{|c|}{ Including with average per capita cash income per month, rub .: } \\
\hline до 9000,0 & 20,5 & 16,6 & 14,2 & 11,3 & 11 & 10,2 & 9,5 \\
\hline above 9000 , I below 20000,0 & 37,4 & 35,6 & 34,2 & 32,1 & 31,9 & 31,3 & 30,2 \\
\hline above 20000 , I below 30000,0 & 18,5 & 19,6 & 20,2 & 20,8 & 20,8 & 21,1 & 21 \\
\hline above 30000 , I below 40000,0 & 9,7 & 11 & 11,8 & 12,8 & 13 & 13,2 & 13,5 \\
\hline above $40000, \mathrm{I}$ below 50000,0 & 5,4 & 6,3 & 7,0 & 7,9 & 7,9 & 8,2 & 8,5 \\
\hline above 50000,1 below 60000,02 ) & 8,5 & 3,8 & 4,2 & 4,9 & 5,0 & 5,2 & 5,4 \\
\hline above $60000, \mathrm{I}$ below 70000,0 & $\ldots$ & 7,1 & 2,7 & 3,1 & 3,2 & 3,3 & 3,6 \\
\hline above 70000,0 & $\ldots$ & $\ldots$ & 5,7 & 7,1 & 7,2 & 7,5 & 8,3 \\
\hline above 2000000 & & & & & & 0,00000 & \\
\hline
\end{tabular}

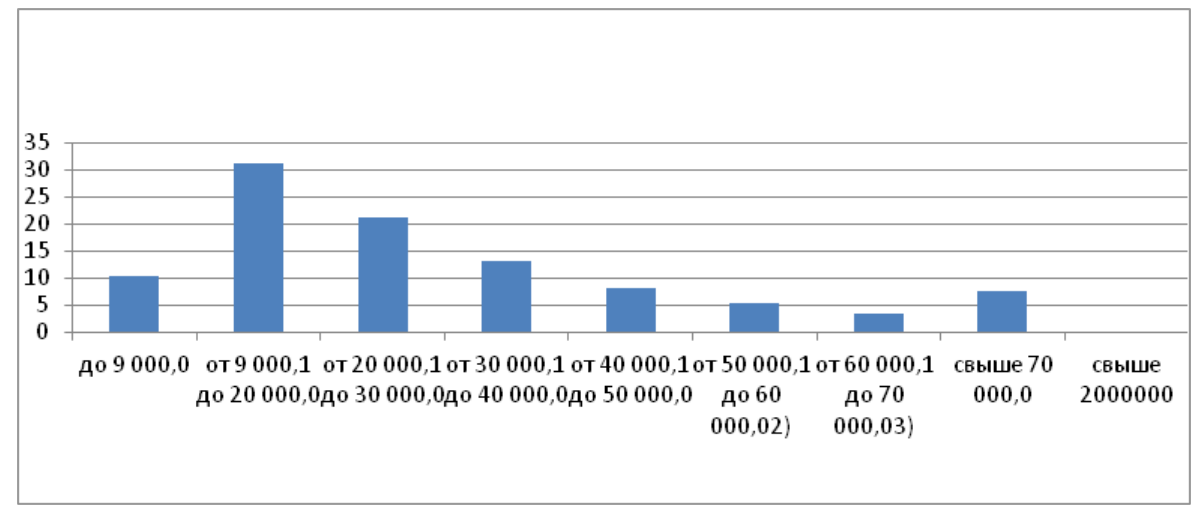

Graph I 
Thus, we have at our disposal a set of data on the basis of which management decisions are made, but there is no mathematical model and methods for preparing and making these management decisions. In our work, for the approximation of average per capita monetary incomes for citizens, we suggest using the so-called Lorenz curveswidely used tools for analyzing economic inequality. ${ }^{3}$ Suppose that the population is $\mathrm{N}$, and the incomes of the population correspond to a certain function. This function means the percentage of the population that has an income below w. For example, according to the data of 2012, F $(9000)=20.5$ corresponds to the fact that $20.5 \%$ of the citizens of the Russian Federation at that time had an income of less than 9000 rubles. The function $\mathrm{F}(\mathrm{w})$ has the following properties:

i. There is a level such that equality $=0$ holds for all, i.e. there is a certain subsistence minimum which nobody lives worse than;

ii. The function $\mathrm{F}(\mathrm{w})$ is cumulative in nature and always increases, since the greater the level of income w, the greater the percentage of the population has an income below this certain level.

Then the proportion of the population with an income from $\mathrm{w}$ to $w+\Delta w$ is $F(w+\Delta w)-F(w)=\Delta F(w)$ (by definition). Thus, with a small $\Delta w$ number of people receiving income $\mathrm{w}$, is determined by the formula $N . \Delta F(w)$ where $\mathrm{N}$ is the total population, and $\operatorname{dif}_{N . \Delta F . w}$ its share corresponds to a certain level of income. The income of this population group is $N . \Delta F(w) . w$

where $\mathrm{N}$ is the total population, $\Delta F(w)$ the proportion corresponding to a certain income level, $w$ is the income for which relevant statistics are available, and the total income of the entire population for all $\mathrm{w}$ is $\sum w \Delta F(w) N$. Or $\int w d F(w)$ The Lorentz function $\mathrm{L}(\mathrm{w})$ is the ratto of the total income of the layer of the population to the total income of the entire population. In this way:

$$
L(w)\left(N \int_{0}^{w} Z d F(Z) /(N . W)\right)=(1 / \mathrm{W}) \int_{0}^{w} Z d F(Z) .
$$

A useful variant of the Lorenz curve is the equality gap curve, defined as the difference between the Lorenz curve and the line of perfect equality. This curve provides a direct illustration of how this distribution deviates from the situation of equal distribution (the line of ideal equality), (see Figure 1).

Lorenz curves can also be used in many other contexts. In essence, the curve shows how one variable is distributed into groups determined by the conditions of another variable. The transition to a quantitative description of the behavior of the social system will show that the inclusion of data on the average per capita income of citizens in the model significantly changes the shape of the Lorentz curve. For example, using the Lorenz curve, which characterizes the uneven distribution of the average per capita monetary income of the social system between different groups of the population in 2018 and 2017, one can show, respectively, in Fig. 1.2, "slyness" of the given initial data. The graphs of the Lorenz curve show that the highest likelihood of the distribution of per capita cash income is shown for 2017, despite the fact that the calculations made assumptions. In any case, the scale was kept along the axis and a huge gap in income was seen.

For 2018, the Lorenz curve is not consistent, this is especially evident from its initial and final segments. This situation will be observed for the remaining years, 2012-2016, as for them are not indicated in excess of income. Thus, in the future, we will conduct the modeling of the stability of the social system, focusing on the data for 2017 (Table 4).

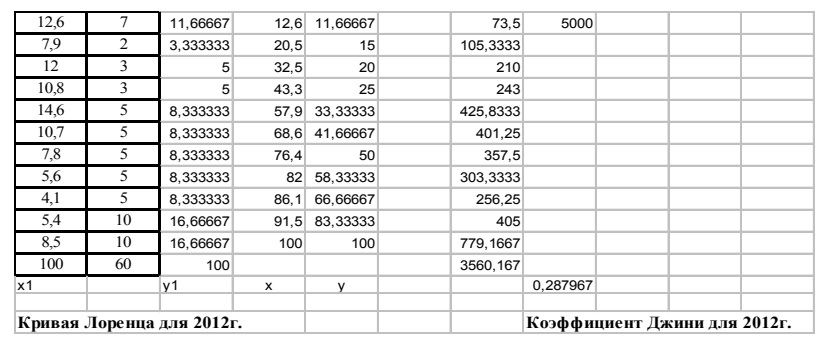

Figure 3 Calculated data for 2012 to build the Lorenz curve and get the gini coefficient.

The table below shows the equations of approximation of the Lorenz curve for the corresponding years and the coefficient of agreement of these equations. To approximate the Lorenz curve, we used a second-order polynomial of the form $y=a x^{2}+b x$. As can be seen from the table, the coefficients of the equation and their signs remain stable throughout the seven years for the available data. Thus, we can conclude that the Lorenz curve approximates quite well the distribution of the population by the average per capita cash income. (Figure 3) presents the calculations for 2012 to build the Lorenz curve and obtain the Gini coefficient. Similar calculations were performed for the remaining years. The Lorentz curves were constructed (Figure 3 ) and the Ginny coefficients were obtained (Table 4). Moreover, it should be noted separately that the initial data for 2017, taking into account super-profits, were transformed into approximately $20 \%$ of the group (see Figure 3), since greatly increased the scale of calculations due to the accounting of super profits.

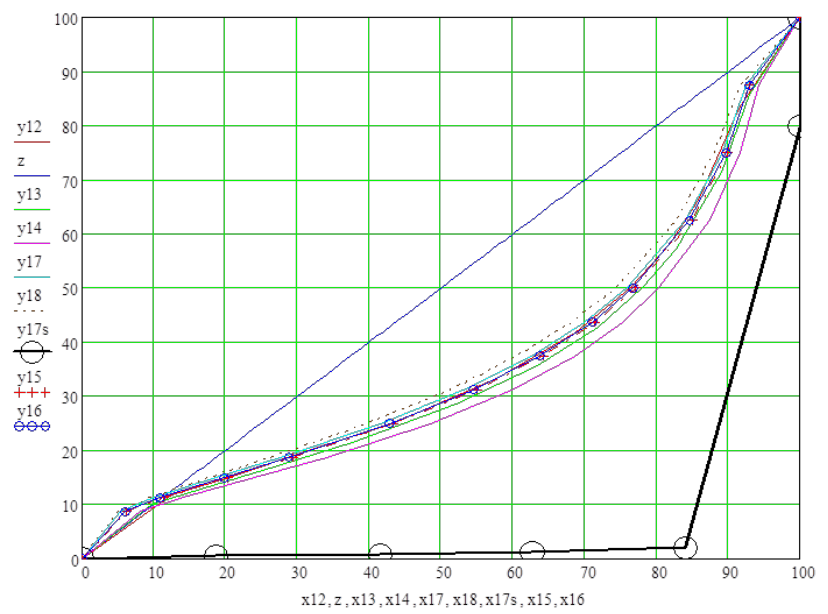

Figure 4 Lorenz curves for 2012-2018 and 2017 taking into account superprofits (y|7s).

Table 5 Estimated Gini Ratio coefficient

\begin{tabular}{|c|c|c|c|c|c|c|c|}
\hline Year & 2012 & 2013 & 2014 & 2015 & 2016 & 2017 & 2018 \\
\hline Gini coefficient & 0,287967 & 0,3106 & 0,344263 & 0,289463 & 0,283813 & 0,269688 & 0,246325 \\
\hline \multicolumn{6}{|c|}{ Gini coefficient taking into account super-profits } & 0,853916 & \\
\hline
\end{tabular}


It should be noted that the Lorenz curves are reflected by piecewise linear functions, which on the one hand is very convenient, since There is no need to select approximating functions. In addition, it is not difficult for them to calculate the Gini coefficient. But on the other hand, the graphical interpretation of the results does not bring us closer to the mathematical model of the stability of the social system (Figures 4, 5 \& Table 5).

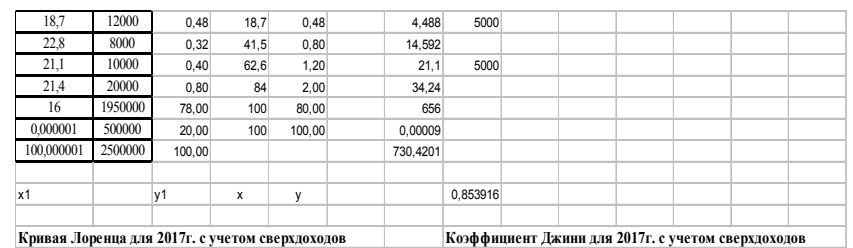

Figure 5 Estimated data for 2017 (including super incomes) for building the Lorenz curve and obtaining the Gini coefficient.

Analyzing the data in the (Table 4), it can be said that, until 2014, the uneven distribution of income increased to 0.344263 , then for 2015-2018. there is a decline to 0.246325 . All this creates a blissful picture of the development of income distribution. Data inclusive of income over 2017 still show the cunningness of official statistics. The Lorenz curve is characteristic not only for income distribution within the state, but also within smaller social groups (enterprise, industry, etc.) The stability of the Lorenz curve over the past seven years shows that despite the fact that the share of the population with an income of less than 9,000 rubles has decreased in recent years from $20.5 \%$ in 2012 to $9.5 \%$ in 2018 , or from $10.1 \%$ of the total income of the population in 2012 to $3.3 \%$ in 2018 , in general, changes in the social system were not significant. It can be assumed that these changes are primarily caused by inflation and a change in the corresponding scalable factor.

The similarity of the curves also leads to the conclusion about the similarity of social systems. ${ }^{5}$ The very type of the curve (second-order polynomial) suggests that, unlike biological systems, social systems cannot be modeled on the assumption that there is no interaction between the elements of the system. ${ }^{6}$ Moreover, it is precisely because of the interaction and the presence of an appropriate structure, for example, in the form of social networks, such income distribution can exist. $^{7}$

In addition, if we are guided by the type of curve, it can be assumed that the existence of this structure of income distribution is not possible without direct support from the state, whose elements are hierarchically subordinate and form an appropriate structure that ensures interaction between the elements of the system. According to the researchers of the World Laboratory of Economic Inequality, the level of economic inequality in modern Russia is comparable to the pre-revolutionary indicators, follows from the report on inequality in the world. If we arrange all adult Russians by income level and divide into two halves, then the first group will account for only $17 \%$ of the national income in 2016 , the second $-83 \%$. At the same time, incomes of the richest $10 \%$ of citizens make up $45.5 \%$ of the national income. Thus, $10 \%$ of richest Russians in 2016 accounted for $45.5 \%$ of national income. For comparison: in Europe for the top decile ( $10 \%$ of income) the share of national income was $37 \%$, in China - $41 \%$. But in North America (USA and Canada), the richest $10 \%$ of citizens concentrate even more income - 47\%, in India and Brazil altogether $55 \%$. The highest level of inequality is recorded in the Middle East, where the top $10 \%$ accumulated $61 \%$ of national income.

The transition from a planned administrative economy to a market economy after the fall of the Soviet Union led to a sharp increase in economic inequality. If in 1990-1991, the share of $10 \%$ of the richest citizens was less than $25 \%$ of the national income, then by 1996 this figure had risen to $45 \%$, and the share of incomes of the "poor" half of the population had dropped from 30 to $10 \%$. Now the poor $50 \%$ accounts for $17 \%$ of the national income. According to researchers, the country experienced the most favorable period in terms of economic equality during the so-called "golden five-year plan" (1966-1970). In 1968, the share of the less well-to-do half of the population accounted for more than $31 \%$ of the income, while the richest $10 \%$ of the population accounted for $21.6 \%$. The level of inequality in the Gini coefficient in 2016 was 0.414 (the indicator takes values from zero in the case of absolute equality to unity in the case of absolute inequality), follows from the preliminary data of Rosstat. In 1996, the coefficient was 0.387 , in 2000 it rose to 0.395 , and in the precrisis 2013 it was 0.419 . The share of the economically vulnerable population in Russia exceeds $50 \%$ and continues to grow, the World Bank noted in a report on the Russian economy. The population of Russia with incomes below $\$ 10$ per day increased to $53.7 \%$, while $13.8 \%$ of Russians spend less than $\$ 5$ per day.

It would seem that the Russian Federation is quite similar to a number of states in terms of income structure, moreover if we had the Lorentz curve of the form $\mathrm{y}=\mathrm{x}$, then in this case the state's development strategy would be jeopardized, since complete financial equality is possible only if there is over excessive resources (which is not observed, especially in terms of financial resources), or in the case of a rigid distribution of finances, in which only small fluctuation fluctuations are possible. Such a situation will completely level the differences between citizens and lead to a lack of incentives for development. The existing situation on the distribution of income, on the contrary, creates prerequisites for development, since there is a large group of people with a low income level and a significant surplus of funds concentrated on a small group of citizens. This situation allows China to develop quite successfully, where the richest $10 \%$ of citizens concentrate $41 \%$, North America (USA and Canada) $47 \%$, India and Brazil 55\%. It should be borne in mind that in these countries the consumption structure is completely different, since Russian citizens spend a significant portion of their income on utility bills and food, as well as a different age distribution, since people of no working age are the least well-to-do citizens in the Russian Federation

Thus, taking into account these factors allows us to conclude that the prospects for development in the Russian Federation are quite pessimistic. As for the stability of the social system, it is stable for a certain period of time, but the change in external factors (primarily the rise in the cost of utilities or food, which, although regulated by the state, is advancing compared to income) can bring the system out of balance and as a result, lead to an increase in crime in the country. We also note that in the case of orientation, when making decisions only on quantitative source data, the state must make considerable efforts to regulate (often manually) the parameters of the system's stability. In the case of the Lorenz curve, the decision is based on the visualized data and takes less time.

\section{Acknowledgments}

None.

\section{Conflicts of interest}

The author declares that there are no conflicts of interest. 


\section{References}

1. Lebedev A, Shmonin A, Vasiliev F, et al. Principles of mathematical models constructing based on the text of qualitative data of social systems. 2019;181:29-38.

2. Hyndman, RJ, Fan Y. Sample quantiles in statistical packages. The American Statistician. 1996;50(4):361-365.

3. Abdelkrim A. Stata module to estimate Lorenz and concentration curves. Statistical Software Components S456515, Department of Economics, Boston College. 2005.

4. Lebedev AB. Information support of the decision-making process in the
Federal Penitentiary Service of Russia. Bulletin of the Vladimir Law. Institute of the Federal Penitentiary Service of Russia. 2011;3(20):3845 .

5. Jørgensen SE, Fath Brian. Modelling the selective adaptation of Darwin's Finches. Ecological Modelling. 2004;176(3):409-418.

6. Lebedev AB, ME Rychago, RN Tikhomirov. A mathematical model for assessing the resource support of a social system. Tomsk State University Journal. Vladim. 2018;1(46):51-55.

7. Sukhodolov AP. Mathematical methods in law enforcement: issues of countering extremism in social networks. All-Russian Criminological Journal. 2018;12(4):468-475. 